\title{
Preliminary Study on Scanning Electron Microscopy as an Additional Mean to Assess the Effectiveness of Sterilization of Endoscopes Used in Digestive Tract Examination
}

\author{
DELIA EUGENIA BERCEAN (VITAN) ${ }^{1,2}$, RAHELA CARPA ${ }^{3 *}$, DOINA PRODAN $^{4}$, \\ MARIOARA MOLDOVAN ${ }^{4}$, CRISTINA BORZAN ${ }^{1}$ \\ ${ }^{1}$ Iuliu Hatieganu University of Medicine and Pharmacy Department of Community Medicine -Public Health and \\ Management, 8 Victor Babes Str., 400012, Cluj-Napoca, Romania \\ Regional Institute of Gastroenterology and Hepatology Prof. O. Fodor Cluj-Napoca, 5 Constanta Str., 400158, Cluj- \\ Napoca, Romania \\ ${ }^{3 *}$ Corresponding author: Rahela Carpa, Babes Bolyai University, Faculty of Biology and Geology, Department of \\ Molecular Biology and Biotechnology, 1, M. Kogălniceanu Str., 400084, Cluj-Napoca, Romania \\ ${ }^{4}$ Babes Bolyai University, Raluca Ripan Institute for Research in Chemistry, 30 Fantanele Str., Cluj-Napoca, Romania
}

\begin{abstract}
Microbiological analyses are performed to check the quality of reprocessing procedures and represent a regular instrument of quality control in gastrointestinal endoscopy. They help detecting and redressing the possible flaws of the reprocessing procedure, thus preventing the transmission of germs through endoscopy. In this paper the effectiveness of sterilization is characterized and compared by scanning electron microscopy and by classical microbiological analyses, for three types of medical devices, with two sterilization methods. The high level manual sterilization method is superior to the automatic reprocessing sterilization method. The sterilization time is important because after changing the immersion in disinfectant period, from 15 minutes to 20 minutes, no more microbial forms were detected, neither at microbiological examination nor at SEM analysis.
\end{abstract}

Keywords: sterilization methods, endoscope, scanning electron microscopy, digestive endoscopy

The gastroenterology field continues to extend and endoscopy is a diagnosis procedure widely used. Though transmission of infectious organisms during gastrointestinal endoscopy is considered to be very rare, it is essential to identify the access ways of these infectious organisms. The inadequate decontamination procedures were the main cause of infections, device malfunction being the second contamination cause. Spaulding classification system is frequently used to determine the adequate sterilization or disinfection type for the medical devices [1]. The manual cleaning of endoscopes is essential, seeing the organic residues and microorganisms coating leading to biofilm forming [2]. Most present flexible endoscopes can not be heat sterilized, and they have more canals and orifices exposed to body fluids, being hard to clean and disinfect [3]. The biofilms growing within endoscope canals can lead to failure of endoscope reprocessing and is an important factor in pathogenesis of endoscopic infections $[4,5]$. The most encountered microorganisms during endoscopy are Gram-negative bacteria (Pseudomonas aeruginosa, Serratia marcescens and Salmonella species), mycobacteria and yeasts [4-6]. P. aeruginosa (Gram-negative) is known to prefer a wet environment (for instance, the wet canals of the endoscopes after reprocessing), being the most frequently responsible for infection transmission during gastrointestinal endoscopy [7]. The infections transmitted by endoscopes can be of endogenous or exogenous nature. The infections caused by the microbial flora of the patient (endogenous) can not be prevented by disinfection procedures, being caused by Escherichia coli, Klebsiella, Enterobacter and enterococci [6]. Infections caused by exogenous microorganisms, most frequent associated with $P$. aeruginosa in gastrointestinal endoscopy [7], can be prevented by strict endoscope disinfection procedures. Exogenous microorganisms can be transmitted from prior patients of from contaminated reprocessing devices [8]. There are though control standards for the infection caused by reprocessing of flexible gastrointestinal endoscopes [2]. Kovaleva and Buss assume that over $91 \%$ of the identified infections could be prevented if the control systems are improved [9]. Accordingly, the strict and scrupulous keeping of the cleaning protocols is essential, in view of reprocessing, in order to prevent contamination between patients and hospital-acquired infections [10]. Efficient cleaning represents the best defence against biofilm forming [11].

*email: k_hella@yahoo.com 
The disinfectants used at reprocessing of flexible endoscopes should be tested according to EN 14885 standard [12]. The needed action for disinfection should include: bactericide, mycobactericide, fungicide and virucidal. If a rinsing agent is used to improve the drying of endoscopes, the toxicological characteristics should be evaluated according to ISO 109993-1, because the substance rests on the endoscopes surface [13, 14].

The combination between different cleaning and disinfecting products can cause compatibility problems, thus the producer recommendations must be always kept. Any kind of residue can constitute a worrying reason regarding microbial growth. The endoscopes can have a normal bacterial load of 108-10 (8-10 log10), while the standardized lead to an 8-12 $\log 10$ decrease in microorganisms. Consequently, the safety margin is very low, at $0-2 \log 10$, so it is necessary to keep the standardized protocols [14].

The aim of this study was to investigate the efficacy of sterilization on some medical devices, by two sterilization methods, and to compare these, by Scanning Electron Microscopy (SEM) and classical microbiological analysis. The hypotheses were: $\mathrm{H}_{0}$ - after performing of the sterilization protocol for flexible digestive endoscopes there is no risk of microbiological transmission. $\mathrm{H}_{1}$ - after performing of the sterilization protocol for flexible digestive endoscopes there is a risk of microbiological transmission.

\section{Experimental part}

Protocol 1-used for manual high level disinfection of endoscopes was the standard one of the Society of Gastroenterology Nurses and Associates (SGNA) [15].

a) Pre-cleaning or preliminary cleaning begun at the patient examination table, soon after the end of the endoscopic procedure, by removing the biological products in a great measure, by irrigating the endoscopic canal 250 $\mathrm{mL}$ of enzymatic detergent solution. This way the permeability of the canal was checked and any rest of blood, mucus or other biological product was expelled. The outer wiping of the endoscope with a mull compress followed, whereafter the endoscope was introduced in a box with top and taken to the sterilization station, in the toolbox cleaning area.

b) The verification of the permeability and leakproofness of endoscope parts was done by air blowing with a special kit destined for (Lenkage Teaster) and was followed by disassembling of the detachable parts of the endoscope.

c) Manual cleaning or actual cleaning consisted of: 5 min dipping of endoscope and its components in the dish with Gigazyme (enzyme cleaning agent for cleaning endoscopes, which contains nonionic tensides and enzymes), followed by brushing, with a special brush, of all the accessible canals, as well as the valves and the exterior surface of the endoscope.

d) Rinsing after cleaning, by which the detergent remains are removed, was done with tap water

e) High level disinfection was done by endoscope dipping in the dish with active disinfectant for medical instruments, $2 \%$ solution of Sekusept Aktiv (contains peracetic acid) and are kept immersed for 15 min, the solution is daily prepared

f) Rinsing after high level disinfection was done with sterile water by introducing it through all the canals of the endoscope.

g) Drying and depositing of endoscope was done by placing it vertically in the specially destined chest.

Protocol 2 performed during research after P1 analyzing the results obtained from application of standard protocol

In the present research, the presence of coccus form bacteria, highlighted by SEM analysis, arose the problem of the efficiency of the sterilization methods currently used in the healthcare establishment with beds. We developed a new protocol, starting from the standard one, which only modified the immersion span in high level disinfectant, of 15 minutes (Protocol constantly applied in the healthcare unit the research was done in), to $20 \mathrm{~min}$, according to the data in the literature [15-17]. In the literature it is considered that, for inactivation of bacterial spores with 500 to 10.000 ppm, immersion in peracetic acid between 15 seconds and 20 minutes is needed.

\section{Protocol 3. Automatic reprocessing}

Before being introduced in the automatic machine the endoscope was subjected to the following operations: precleaning and manual cleaning - brushing. Than the endoscope and its accessories were placed within the machine, in the special spaces. The automatic machine for washing endoscopes and accessories used in our study was ETD4 (Olympus producer) [18] with a reprocessing capacity of two flexible endoscopes and their accessories in a single cycle. The mechanism is equipped with a completely automatized tightness testing device with an integrated overpressure clack. The dosage of the chemical substances used (the ones recommended by the Olympus producer) is quantitatively monitored, by a dosage control system. It is equipped with an UV unit which emits UV radiations, which assure an adequate sanitizing quality of the water used in reprocessing and for quick drying warm air is used, filtered with HEPA filter, heated and circulated by the dryer [18]. 
The Standard Dry Programme of automatic endoscope washing machine was used, which has the following stages: the sealing test, preliminary cleaning with water at $20^{\circ} \mathrm{C}$, cleaning with water at $55-57^{\circ} \mathrm{C}$, the first rinsing with deionized water (Aq. dist.); disinfection, the second rinsing, finale rinsing, cooling and drying. The duodenoscope was sterilized with the automatic machine for washing endoscopes and medical accessories.

\section{Protocol 4 of sampling}

The samples used in the study were taken from a healthcare unit specialized in gastroenterology, which, within the Diagnostic and Therapeutic Digestive Endoscopy Compartment, performs both diagnostic investigations and treatment of the alimentary duct. Endoscopic retrograde cholangiopancreatography is performed to extract biliary calculi or for prosthesing of the pancreatic and biliary duct, by duodenoscope; superior digestive endoscopy, by gastroscope, or inferior, using diagnosis colonoscope, for detecting lesions and their biopsy or with therapeutic purpose for endoscopic hemostasis. In average, annually, 19.619 endoscopic examinations are done. In the sampling day, in the Endoscopy Compartment, 37 endoscopic examinations were done. The endoscopes subjected to examination were randomly selected.

The samples were taken by the medical staff, aseptically and with sterile materials, keeping the Sampling Protocol, according to annex 2 from the Order No. 961/2016 issued by Ministry of Health [19].

\section{Protocol 5 Microbiological cultivation on plates}

Universal transport media were used, based on the principle of Stuart medium, which is a semi-solid medium, which protects the numerous microorganisms from the self-lysis effects and the terminal effects of oxidation (gonococci, haemophili, Bordetella pertussis, salmonellas, staphylococci, streptococci, pneumococci). It ensure the survival of bacteria for 24-72 hours [20].

In the collecting recipient, over the sampling swabs $9 \mathrm{ml}$ of physiologic serum were added, vigorously stirring. A 1/10 dilution was obtained, after which another decimal serial dilution with $9 \mathrm{ml}$ normal saline dilution was done, resulting a 1/100 dilution. Out of each dilution, $0.1 \mathrm{~mL}$ were dispersed on a plate of nutrient agar with blood and lactose medium and incubated for $24-28 \mathrm{~h}$ on thermostat at $37^{\circ} \mathrm{C}$. After incubation the number of colonies appeared on plates was calculated according to the formula:

$$
c f u / 25 \mathrm{~cm}^{2}=\frac{\sum(n \times d)}{N} \times 100 \mu l,
$$

where: $\Sigma$ = amount; $\mathrm{n}=$ medium colonies number; $\mathrm{d}=$ dilution of inoculated plate; $\mathrm{N}=$ number of plates taken into account; $100 \mu \mathrm{L}=$ volume inoculated on plate [21].

\section{Protocol 6 Preparing the samples for investigation at SEM}

For investigation at scanning electron microscope, swabs with sterile culture medium were incubated for 24 hours at $37^{\circ} \mathrm{C}$. After incubation, in the chemistry lab, out of each sample were extracted from three different zones, with a sterile tuck, a few fibers from the sample swab and were placed on the layer of the adhesive double carbon strip on the rack. The examination of the microstructure of the samples surface was done by Inspect S (FEI Company, The Netherlands) scanning electron microscope. The determinations were performed in low-vacuum, at $80 \mathrm{~Pa}$ pressure, at $15 \mathrm{kV}$, and an $11 \mathrm{~mm}$ working distance.

Three research lots were established: Lot 1 control; Lot 2 research; Lot 3 research.

\section{$\underline{\text { Lot I control }}$}

Samples taken from the extern surfaces, on new endoscopes, never used before, of the three types: duodenoscope, gastroscope and colonoscope. One sample was taken from each endoscope type.

Endoscopes including criteria: 1) single producer: Olympus Medical Systems Corp; 2) new endoscopes, unsealed in the moment of samples taking; 3 ) endoscopes with a maximum 8 years average working period.

Endoscopes excluding criteria: 1) endoscopes produced by other companies; 2) used before sampling; 3) physically damaged; 4) over 8 years of operation period.

Sampling: the sterile swab was used to take samples from the side parts of the duodenoscopes, in the zones of the operating canal and of the flap; at gastroscope and colonoscope the sampling was done at their tips. For each determination, the swabs passed 3 to 4 times on the specified zones. Subsequently they were introduced in the test tube with Amies transport medium, based on the principle of the Stuart medium. The taken samples were transported in the microbiology lab of "Prof. O. Fodor" RIGH of Cluj-Napoca, for inoculation and incubation, as well as in the chemistry lab (RRRI Cluj) for SEM.

\section{$\underline{\text { Lot II research }}$}


It was realized out of samples taken from the same type of endoscopes, after finishing the current sterilization, according to the standard protocol, performed in the healthcare unit in which the study was done.

Endoscopes including criteria: 1) single producer: Olympus Medical Systems Corp; 2) endoscopes used prior to sampling, chosen on the temporal criteria of provenance from the same sterilization lot (endoscopes used in the same day for digestive investigations and included in the same day in the sterilization process) endoscopes with maximum 8 years of operation period

Endoscopes excluding criteria: 1) endoscopes produced by other companies; 2) endoscopes sterilized according to the new protocol; 3) physically damaged, obsolete over 8 years of operation period.

\section{Lot III research}

It was realized out of samples taken from the same type of endoscopes, namely gastroscopes, sterilized according to the newly proposed protocol (Protocol 2).

Endoscopes including criteria: 1) single producer: Olympus Medical Systems Corp; 2) endoscopes used prior to sampling, chosen on the temporal criteria of provenance from the same sterilization lot (endoscopes used in the same day for digestive investigations and included in the same day in the sterilization process); 3) the average operation period is 8 years; 4) endoscopes sterilized according to the newly proposed protocol.

Endoscopes excluding criteria: 1) endoscopes produced by other companies; 2) physically damaged, obsolete; 3) over 8 years of operation period endoscopes sterilized according to the old protocol.

Including criteria for samples: 1) bacterial samples taken according to Annex 2 of Order No. 961/2016 issued by HM (for lots I, II and III); 2) bacterial samples taken according to the modified Protocol, proposed by the researcher (protocol 2); 3) samples taken in the same day.

Excluding criteria for samples: 1) samples incorrectly taken, transported;2) samples taken out of the sampling day.

\section{Results and discussions}

Microbiological investigation by plate culture

Lot I control: for the microbiologic analysis the plate culture was performed, on the two culture media (blood agar and lactose medium). The result for the control samples was negative, germs did not develop (Figure 1: a, b,c).
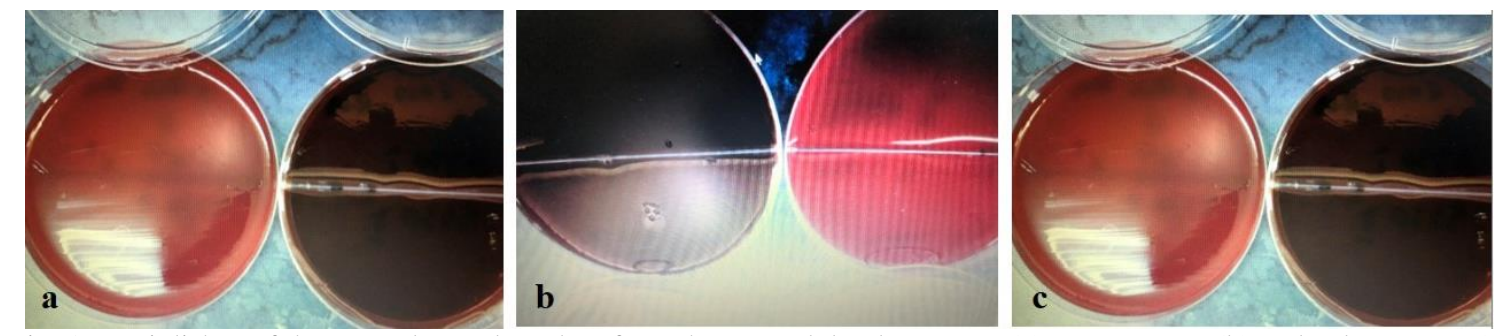

Fig. 1. Petri dishes of the control samples taken from the unused duodenoscope (a), gastroscope (b) and colonoscope (c)

At lot II, samples taken from used and sterilized endoscopes, by methods described in Materials and Methods chapter and inoculated according to the research protocol, did not reveal the presence of germs at plates level (Figure $2 \mathrm{a}, \mathrm{b}, \mathrm{c})$.
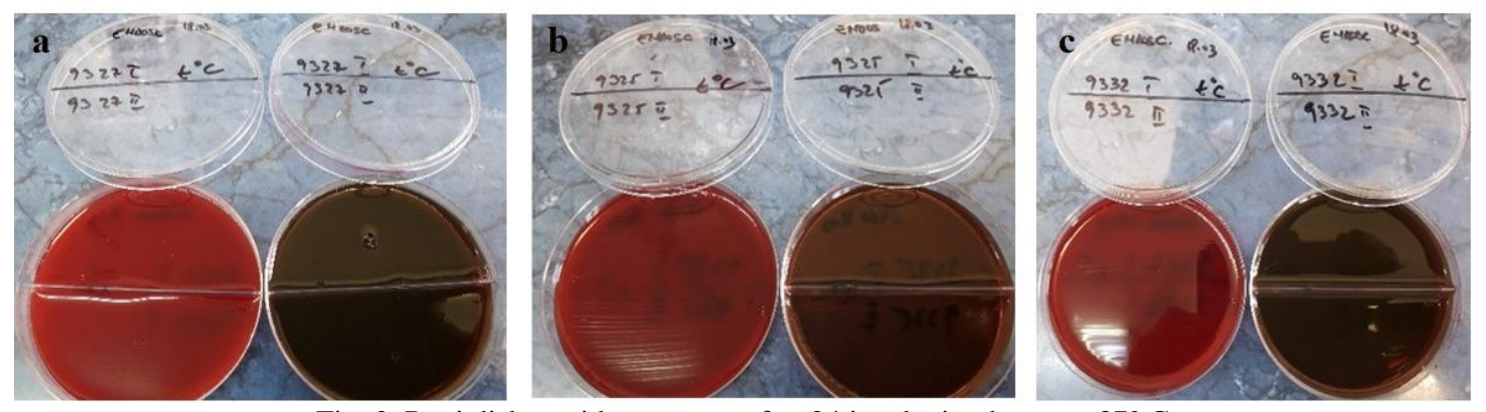

Fig. 2. Petri dishes without germs after 24 incubation hours at $37^{\circ} \mathrm{C}$

Investigation by screening electron microscopy

1) For the control samples taken from unused endoscopes, following the screening electron microscopy investigation there is no form of matter to indicate a bacterial colonization (Figure 3). 

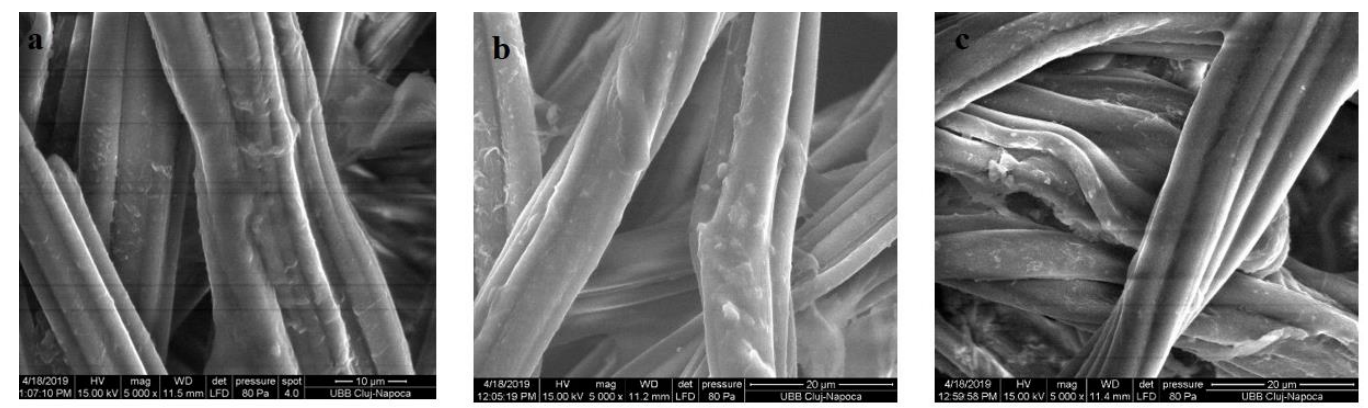

Fig. 3. SEM images of the control samples taken from the unused a) Duodenoscope $\mathrm{x} 5000$,

b) Gastroscope $x 5000$ and c) Colonoscope x 5000

2) For the samples of Lot II of research by scanning electron microscopy some bacterial forms were detected between the cellulose fibers of the sampling swab in the case of duodenoscope (Figure $4 \mathrm{a}, \mathrm{b}$ ) and gastroscope (Figure $5 \mathrm{a}, \mathrm{b})$.

In fig. 4-5 SEM images can be visualized on the surface of the fibers taken from the swabs each endoscope was wiped with, after the sterilization process (disinfection). At SEM examination the three fiber clusters, randomly taken from swabs, the following were noticed:

At the sample from duodenoscope, the presence of coccus form bacteria was noticed on two of the three fiber clusters examined, at magnitudes of 5000 and 10000 larger. These were placed either separated or grouped (Figure 4 a, b).
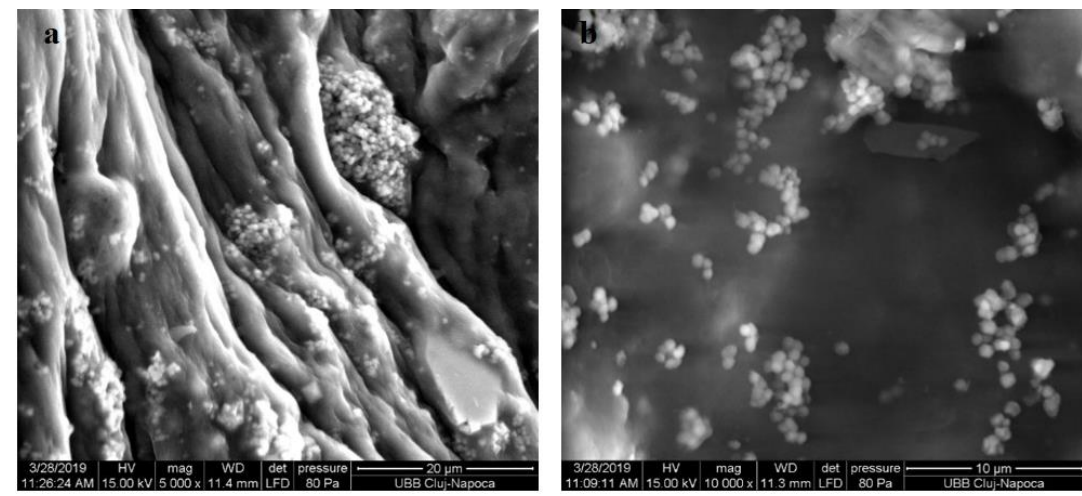

Fig. 4. SEM images at a) x5000 b) x10000 magnitudes on the sample taken from the duodenoscope, after automatic reprocessing

At the sample taken from gastroscope the presence of coccus type bacteria was noticed on a zone from a single fibers cluster, out of the three fibers cluster examined (Figure 5). At this sample the presence of bacteria was much lower.
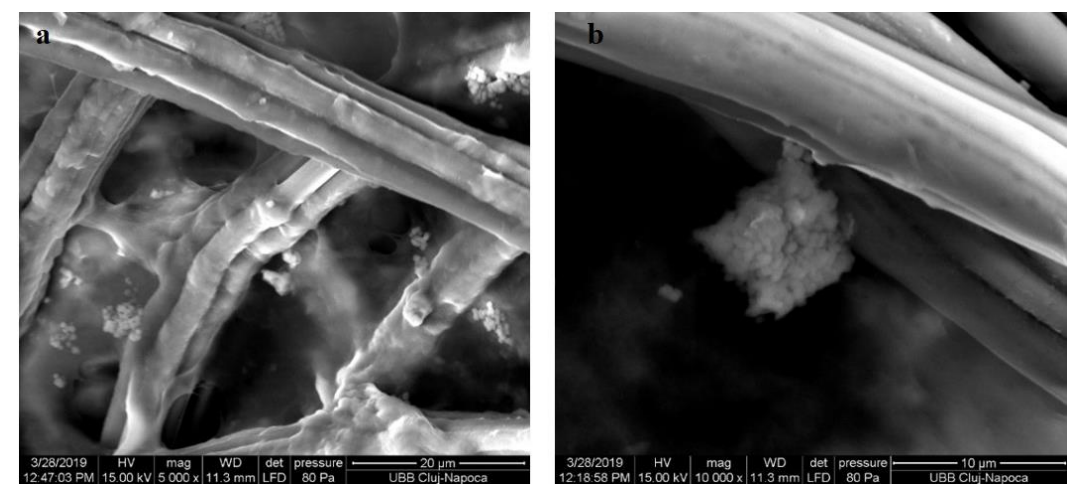

Fig. 5. SEM images at a) x5000 b) $\mathrm{x} 10000$ magnitudes on the sample taken from gastroscope, after high level manual disinfection

3) For the samples from research lot III, taken from gastroscopes sterilized by Protocol 2 - namely the extension of the high level disinfection time at 20 minutes, by screening electron microscopy it was noticed that the microbial forms are completely lacking, as seen in Figure 6. 

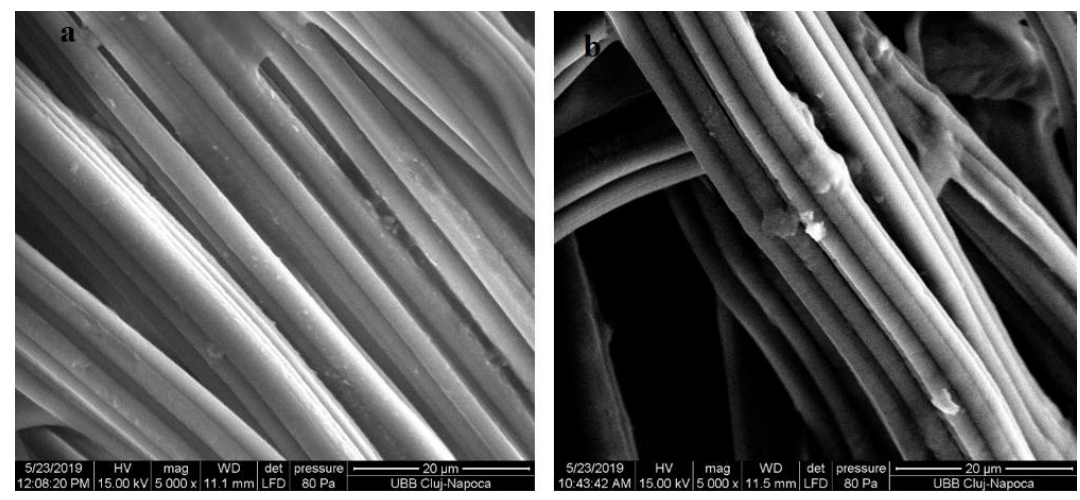

Fig. 6. SEM images at $\mathrm{x} 5000$ magnitudes at the sample taken from gastroscope after the extension of the sterilization period

For the samples of research lot II by screening electron microscopy some bacterial forms were detected between the cellulose fibers of the sampling swab in the case of gastroscope and duodenoscope. At the sample from duodenoscope, the presence of some coccus form bacteria was observed on two of the three. These were placed separately or grouped.

At the sample taken from colonoscope the presence of microbial forms was not observed on none of the three fiber clusters examined (Figure 7).
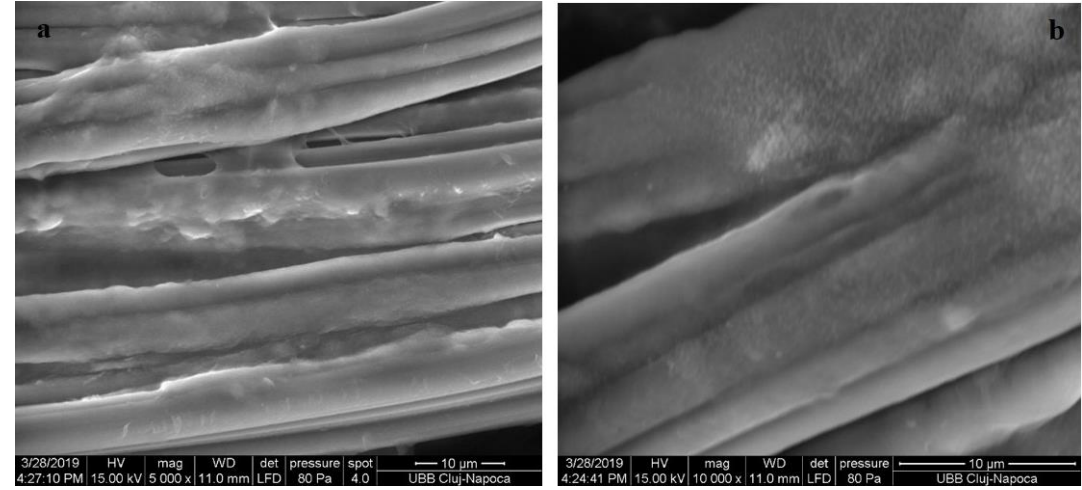

Fig. 7. SEM images at a) x500 b) x10000 magnitudes on the sample taken from colonoscope after manual high level disinfection

Analysis by scanning electron microscopy is useful for surfaces examination, but unfortunately it has its limitations as: dehydrating of samples during examination and observation of small sections which is possible to not fully reflect the characteristics of the whole sample subjected to investigation. Important information on the efficiency of the sterilizing methods could still be obtained. It can be assumed that the presence of bacteria can be explained by the shortcomings of the sterilization methods. As reflected in the literature, the water/air canals of many endoscopes are far too small to be mechanically cleaned, so they require cleaning by chemical means. Unfortunately, some chemical substances used to remove the biofilm are incompatible with the materials used in endoscopes [22].

High level disinfection of gastroscope and colonoscope was done with a 2\% Sekusept Aktiv solution. From the file of the product [23] it can be observed that the active substance of this medical device is the peracetic acid $0.1 \%$, with a concentration higher that $0.1 \%$, while in the working solution the concentration must be $2 \%$. Other ingredients are: sodium percarbonate, citric acid and sodium carbonate.

For many years, Glutaraldehyde was used for the final disinfection of lab instruments. Over time, the use of glutaraldehyde was limited to the healthcare services, trying to replace it with a product as efficient, but not toxic. Peracetic acid is considered to be a strong biocide, even at low concentrations $(0.0001 \%$ up to $0.2 \%)$. The advantage of it is preserving efficiency even in the presence of organic residues and it decomposes into non-toxic and nonmutagenic substances (acetic acid and $\mathrm{O}_{2}$ ). Equally, it ensures an excellent disinfection in a short time span. It is however necessary the setting up of an optimal protocol for using the final disinfection solutions [24-26].

About peracetic acid, as oxidizing agent, it is considered that it functions similar to the hydrogen peroxide at protein denaturation, disturbing the permeability of the cell wall and oxidizing the sulfhydryl groups into proteins, enzymes and other metabolites [16]. This acid can corrode copper, brass, bronze, simple steel and galvanized iron; effects which can be reduced by additives and $p \mathrm{H}$ modifications. Equally, peracetic acid is instable when it is diluted. For example: a $1 \%$ solution reduces its resistance by hydrolysis in 6 days, while at $40 \%$ it loses $1 \%$ to $2 \%$ of its activity on a month span [16]. This will inactivated Gram-positive and Gram-negative bacteria, fungi and yeasts in less than 5 minutes at less than $100 \mathrm{ppm}$ (parts per million). In the presence of organic matter 200 to $500 \mathrm{ppm}$ (parts 
per million) are necessary for inactivation. Bacterial spores are inactivated with 500 to $10.000 \mathrm{ppm}$ (parts per million) between 15 seconds and 20 min $[16,17]$.

Both at duodenoscope and gastroscope the presence of some bacterial forms was noticed. These probably persisted on the devices because some biomaterials with thick surfaces, hydrophobic and positively charged have the tendency to favor microbial adhesion, compared to smooth, hydrophilic and negatively charged materials [27]. Hence, the hydrophobic forces play an important role in microbial adhesion, being 10 to 100 times stronger than van der Waals forces, at $10 \mathrm{~nm}$ distance from the surface of the biomaterial [27]. It is known that the microbial adhesion to biomaterials takes place in the following order: latex $>$ silicone $>\mathrm{PVC}>$ raylon> polyurethane $>$ stainless steel> titanium. The surface characteristics which determine the adherence properties of the specified materials include: surface texture, surface charge and/or hydrophobicity [27, 28]. It is necessary for the biomaterials to be biofunctional and biocompatible, qualities met, among the classic metallic materials, only by the following alloys: $\mathrm{FeCr}-\mathrm{Ni}, \mathrm{Co}-\mathrm{Cr}$ and Ti-Al-V. Alloys based on Ni-Ti can be found at endoscopes [29].

At gastroscope, after extending the immersion period in the high level disinfectant, from 15 to 20 min, bacterial forms were not found anymore.

In the case of the gastroscope from the lot II, a high level manual disinfection was performed. It is told that a main bacterial contamination factor for endoscopes and disinfection machines is represented by the washing/rinsing water. The auxiliary equipment can be contaminated during washing or rinsing, where the organisms can proliferate in the wet zones of the endoscope during storing [30]. At the gastroscope from lot III, after performing protocol 2, namely increasing the immersion period in high level disinfectant to $20 \mathrm{~min}$, no more microbial forms were detected.

According to a recent study, for reprocessing it is recommending to dry the endoscope with forced filtered air. An automatic drying, compared to a usual one, leads to minimizing the bacterial proliferation and protection against transmission of an endoscopy related disease [31].

\section{Conclusions}

The study confirmed the $\mathrm{H}_{1}$ hypothesis and infirmed the $\mathrm{H}_{0}$ hypothesis by using screening electron microscopy.

Screening electron microscopy proved to be a useful supplementary method in assessing the sterilization of the endoscopes used in evaluating the sterilization of the endoscopes used to examine the alimentary duct.

Following the investigation on the efficiency of the sterilization methods for the 3 types of endoscopes, we can claim that the manual high level sterilization method is suitable for endoscope. According to the medical device, even at high level manual disinfection, bacterial contamination forms can occur, as the case in this study (the presence of bacteria at the gastroscope samples from lot II).

The newly developed protocol, applied in the present research, proved its suitability at sterilization of endoscopes used in examination of alimentary duct. Thus, after modification of the immersion in disinfectant time span, from 15 min to $20 \mathrm{~min}$, microbial forms were no longer detected, neither at the microbiological exam, not at SEM analysis. Also, for a complete sterilization, it is essential to extend the disinfection time span for the manual high level disinfection method. We consider that supplementary studies are necessary on the sterilization of endoscopes, in order to ascertain the efficiency of the disinfecting substances.

\section{References}

1. PETERSEN, B.T., CHENNAT, J., COHEN, J., COTTON, P.B., GREENWALD, D.A., KOWALSKI, T.E., KRINSKY, M.L., G.PARK, W., PIKE, I.M., ROMAGNUOLO, J., RUTALA, W.A., Gastrointestinal Endoscopy, 73(6), 2011, 1075-1084

2.***Society of Gastroenterology Nurses and Associates, Inc. (SGNA), Standards of Infection Control in Reprocessing of Flexible Gastrointestinal Endoscopes, 401 N. Michigan Avenue, Chicago, IL, 2012, 60611-4267

3. NELSON, D., BARKUN, A., BLOCK, K., BURDICK, J., GINSBERG, G., GREENWALD, D., KELSEY, P., NAKAO, N., SLIVKA, A., SMITH, P., VAKIL, N., Gastrointestinal Endoscopy, 54 (6), 2001, 824-828

4. BUSS, A., BEEN, M., BORGERS, R., STOKROOS, I., MELCHERS, W., PETERS, F., LIMBURG, A., DEGENER, J.E., Endoscopy, 40 (4), 2008, 327-332

5. KOVALEVA, J., MEESSEN, N., PETERS, F., BEEN, M., ARENDS, J., BORGERS, R., DEGENER, J., Endoscopy, 41(10), 2009, 913-916

6. SPACH, D., SILVERSTEIN, F., STAMM, W., Annals of Internal Medicine, 118(2), 1993, 117-128

7. NELSON, D., MUSCARELLA, L., World Journal of Gastroenterology, 12(25), 2006, 3953-3964

8. SRINIVASAN, A., Current Infectious Disease Reports, 5 (6), 2003, 467-472

9. KOVALEVA, J., BUSS, A., Therapeutic gastrointestinal endoscopy, IntechOpen, 2011, 141-162

10. ALVARADO, C.J., REICHELDERFER, M., American Journal of Infection Control, 28(2), 2000, 138-55

11. NELSON, D.B., Current Opinions in Infectious Diseases, 18, 2005, 326- 330

12. *** EN 14885, Chemical disinfectants and antiseptics - Application of European Standards for chemical disinfectants and antiseptics, 2015

13. *** ISO 109993-1, (Biological evaluation of medical devices - Part 1: Evaluation and testing within a risk management process, 2009

14. *** European Socienty of Gastrointestinal Endoscopy http://www.esge.com/assets/downloads/pdfs /guidelines/2018 a 07591629. pdf

15. *** Standards of Infection Control in Reprocessing of Flexible Gastrointestinal Endoscopes, Society of Gastroenterology Nurses and Associates, Inc. (SGNA), 2012

16. RUTALA, W.A., WEBER, D.J., Infect Control Hosp Epidemiol, 20 (1), 1999, 69- 76

17. BLOCK, S.S., In: Block S.S., PA: Lea \& Febiger, 1999, 167-181 
18. *** Olympus - Endoscopy System Guide instructions for use on the system. Olympus Winter \& Ibe GmbH, 2017

19. *** Ordinul MS nr. 961/2016, pentru aprobarea Normelor tehnice privind curatarea, dezinfecţia si sterilizarea în unitatile sanitare publice si private, tehnicii de lucru şi interpretare pentru testele de evaluare a eficientei procedurii de curatenie si dezinfectie, procedurilor recomandate pentru dezinfectia mainilor, in functie de nivelul de risc, metodelor de aplicare a dezinfectantelor chimice in functie de suportul care urmeaza sa fie tratat si a metodelor de evaluare a derularii si eficientei procesului de sterilizare

20. BUIUC, D., NEGUT, M., Editura Medicală, 2008

21. CARPA, R., DRAGAN-BULARDA, M., MUNTEAN, V., Ed. Presa Univ. Clujeana, 2014

22. PAJKOS, A., VICKERY, K., COSSART, Y., Journal of Hospital Infection, 58(3), 2004, 224-229

23.*** http://medicalcorp.ro/wp-content/uploads/2015/04/FTS-SAX.pdf

24. WUTZLER, P., SAUERBREI, A., Lett Appl Microbiol., 39 (2), 2004, 194-8

25. COSTA, S.A.D.S., PAULA, O.F.P.D., LEÃO, M.V.P., SANTOS, S.S.F.D., Brazilian Oral Research, 29 (1), 2015, 1-6

26. KUNIGK, L., ALMEIDA, M.C.B., Braz J Microbiol., 32(1), 2001, 38-41

27. LAZAR, V., CHIFIRIUC, M.C., Roum Arch Microbiol Immunol, 69(3), 2010, 125-138

28. BORE, E., LANGSRUD, S., J Appl Microbiol., 98(1), 2005, 96-105

29. BUJORENU, L.G., Ed. Junimea, Iasi, 2000

30. *** http://www.chrispqld.com/endoscopy/Documents/14062b.pdf

31. BARAKAT, M.T., HUANG, R.J., BANERJEE, S., GastrointestinaL Endoscopy, 89(1), 2019, 124-132

$\overline{\text { Manuscript received: } 27.07 .2019}$ 